\title{
Diversification in Monkeyflowers: An Investigation of the Effects of Elevation and Floral Color in the Genus Mimulus
}

\author{
Ezgi Ogutcen, Brooklyn Hamper, and Jana C. Vamosi \\ Department of Biological Sciences, University of Calgary, 2500 University Drive NW, Calgary, AB, Canada T2N 1N4 \\ Correspondence should be addressed to Jana C. Vamosi; jvamosi@ucalgary.ca
}

Received 14 August 2013; Revised 16 November 2013; Accepted 20 November 2013; Published 5 January 2014

Academic Editor: Hirohisa Kishino

Copyright (C) 2014 Ezgi Ogutcen et al. This is an open access article distributed under the Creative Commons Attribution License, which permits unrestricted use, distribution, and reproduction in any medium, provided the original work is properly cited.

\begin{abstract}
The vast diversity of floral colours in many flowering plant families, paired with the observation of preferences among pollinators, suggests that floral colour may be involved in the process of speciation in flowering plants. While transitions in floral colour have been examined in numerous genera, we have very little information on the consequences of floral colour transitions to the evolutionary success of a clade. Overlaid upon these patterns is the possibility that certain floral colours are more prevalent in certain environments, with the causes of differential diversification being more directly determined by geographical distribution. Here we examine transition rates to anthocyanin + carotenoid rich (red/orange/fuschia) flowers and examine whether red/orange flowers are associated with differences in speciation and/or extinction rates in Mimulus. Because it has been suggested that reddish flowers are more prevalent at high elevation, we also examine the macroevolutionary evidence for this association and determine if there is evidence for differential diversification at high elevations. We find that, while red/orange clades have equivalent speciation rates, the trait state of reddish flowers reverts more rapidly to the nonreddish trait state. Moreover, there is evidence for high speciation rates at high elevation and no evidence for transition rates in floral colour to differ depending on elevation.
\end{abstract}

\section{Introduction}

The species richness of flowering plant lineages shows tremendous variation amongst clades, indicating that certain traits influence speciation and/or extinction rates. In plants, many traits have been associated with evolutionarily success, such as self-incompatibility [1] and floral asymmetry [2]. The reasons why certain traits are associated with increased diversification are often intuitive: some traits inherently encourage speciation via increased genetic diversity (selfincompatibility) or an association with increased opportunities for the evolution of specialization (floral asymmetry). While geographical distribution might be also influence diversification rates $[3,4]$ because speciation may accompany the establishment in new ecozones [5], the effects of geographical area are far from fully understood [6].

On the one hand, increased geographical extent provides more opportunities for allopatric speciation (i.e., the "geographical potential for speciation" [7]). If increased geographical extent is simply caused by high dispersal rates, however, gene flow is maintained and hinders speciation [8].
The optimal conditions of dispersal for speciation appear to be met in island systems, where many classic examples of adaptive radiations are found [9]. Recent evidence indicates that island-like systems can also be found in mountainous areas [10], suggesting that mountain peaks also provide the right balance between dispersal and isolation to accelerate speciation, yet these patterns are not as well characterized. One reason why mountain peaks may differ from true island systems is that speciation may occur between lowland and high elevation bands as well as between isolated mountain peaks. In flowering plants, the gene flow between lowland and high elevation bands may decline because pollinators differ along elevation clines, potentially leading to floral isolation $[11,12]$.

Pollinating fauna exhibit geographical heterogeneity and these differences in composition could play a central role in why angiosperms display such extreme diversity in floral colour and morphology. Lineages of flowering plants can evolve floral colours and shapes that encourage visits from the most efficient pollinator, a process that leads to the observation of "pollination syndromes" [13]. While the absolute 
nature of pollinator syndromes is debatable and there are numerous examples of exceptions [14], the "bee" functional group is attracted to flowers that are white, yellow, and purple, and birds are noted for their preference for red flowers [4]. Because beetles and flies also often visit white and yellow flowers and infringe on the "bee" portion of the spectrum, the red or reddish hues of the colour palette (including deep oranges, magenta) may be perceived as "catering to a specialized clientele". The selection pressures that are involved in the evolution of specialization are not currently well characterized nor are the downstream consequences of evolutionary transitions between specialization and generalization. For instance, it has been suggested that hummingbirds are more common at high elevations [15] and this may lead to a speciational pollinator shift accompanied by the transition towards reddish flowers at high elevations.

While floral colour is a noted cue to the most common pollinator of a given species, there are other reasons why the evolution of floral colour is observed to be a labile trait. Research on the genetic architecture of floral colour indicates that drastic colour shifts can occur with a number of single loss-of-function mutations [16]. Macroevolutionary analyses that examine trait conservatism versus node-based shifts in floral colour can shed light on (1) whether any particular floral colour is associated with increased diversification or (2) whether shifts in floral colour are involved in the speciation process itself. Here, we examine these patterns within the genus Mimulus, which comprises approximately 120 species [17], mostly restricted to North America [18]. The genus contains a variety of floral morphologies and floral colours [19]. It has been previously shown that there have been multiple shifts from bee pollination to hummingbird pollination within the genus [20]. With ample sequences and robust species-level phylogenies attainable for the genus, the time is ripe for macroevolutionary analysis of diversification patterns in Mimulus within a biogeographical context. With a well-resolved phylogenetic tree, Mimulus presents an ideal system in which to then test whether (1) transition rates to red/orange/fuschia ("reddish") flowers are significantly different from the reverse pathway, (2) "reddish" flowers are associated with higher elevations, and (3) "reddish" flowers are associated with differences in speciation and/or extinction rates in Mimulus.

\section{Methods}

2.1. Dataset. We searched the literature and e-floras (e.g., California Native Plant Society (CNPS, [21]), Calflora [22], Encyclopedia of Life (EOL) [23], and Jepson Herbarium [24]) for qualitative assessments of floral colour of all species of Mimulus. Where these were not available, we scanned online pictures and made our own qualitative assessments of colour. In most cases, it was a very straightforward exercise to discern whether the floral colour was in what we considered "reddish" (RO: red, orange, or fuchsia) or not (no-RO), in other words, possessing both carotenoids and anthocyanins. Quantitative assessments of elevation were obtained from e-floras as well, with the admittedly arbitrary cut-off of being restricted to "high elevation" if a species was restricted to sites $>1000 \mathrm{~m}$ elevation. Similarly, e-floras were also used for assessments of distribution (e.g., Calflora [22], Encyclopedia of Life (EOL) [23], FloraBase [25], United States Department of Agriculture (USDA) - Natural Resources Conservation Service) [26].

2.2. Taxon Sampling and Phylogeny Reconstruction. We compiled the available DNA sequence markers for Mimulus species on the National Center for Biotechnology Information (NCBI) GenBank website (http://www.ncbi.nlm.nih.gov/ genbank/). Our review showed that there are high numbers of species sequenced for 3 markers: (1) trnL gene and trnL-trnF intergenic spacer $(\operatorname{trnLF})$; (2) the internal transcribed spacer region ITS1, the $5.8 \mathrm{~S}$ coding region and ITS2 (ITS); and (3) the external transcribed spacer (ETS). The trnL-F marker is located in the chloroplast, and ETS and ITS markers are located in the nucleus. These three markers were used for our phylogenetic analyses, which included 94 Mimulus species (Table 2).

Mohavea breviflora was used as an outgroup for all analyses, as in previous molecular work [27].

DNA sequences for ETS, ITS, and trnL-F markers were aligned using Mesquite version 2.75 [28] with Opal package [29] using default settings. The same Mesquite package was used to concatenate the DNA markers for each taxon. Analyses were made with combined nuclear markers (ETS and ITS) and for all markers (ETS, ITS, and trnL-F). For partitioned analysis of the combined data, nexus files were manually edited for partition setting, in which each DNA marker was set as an individual partition. The three DNA markers were analyzed both individually and in combination for phylogenetic reconstruction analyses.

Rapid bootstrap analysis and search for a maximum likelihood (ML) tree were performed with Randomized Axcelerated Maximum Likelihood (RAxML) software version 7.4.2 [30] under the general time reversible (GTR) substitution model with gamma rate heterogeneity for all individual and combined data sets. Mohavea breviflora was included as the outgroup prior to analysis. Furthermore, Bayesian analyses were conducted for all data sets using BEAST v1.7.4 [31]. BEAST.xml files for each data set were generated using BEAUti v.1.7.4 [32]. Mohavea breviflora was used as an outgroup, and the ingroup was assigned to be monophyletic prior to analysis. Hasegawa, Kishino, and Yano (HKY) model [33] with gamma site heterogeneity was used as the substitution model due to its general reduction of assumptions. We used the node splitting Mimulus from the outgroup Mohavea as our calibration point for our phylogenetic tree. In order to take calibration uncertainty into account, we used normal distribution as prior to our calibration node with a mean of $76 \mathrm{Ma}$ and standard deviation of 1 [34]. The rest of the node ages were estimated using uncorrelated lognormal relaxed clock model with the mean distribution prior set to gamma. We selected the Yule speciation model $[35,36]$ with uniform distribution as our tree prior. For the Markov chain Monte Carlo (MCMC) analyses, the chain length was set to $10,000,000$ and we logged parameters every 1,000 generations (i.e., at the end of the run, we had 10,000 samples). For 
runs with combined data sets, separate models were allowed for each partition. Maximum clade credibility (MCC) trees were generated using TreeAnnotator version 1.7.4 (part of the BEAST package) with the first 50 steps discarded at the start of the run.

\subsection{Phylogenetic Comparative Analysis}

2.3.1. Macroevolution of Reddish Flowers. We used the binary-state speciation and extinction (BiSSE) method [37] implemented in the "diversitree" package [38] of the $R$ statistical software [39] to examine differences in transition rates between character states as well as differences in speciation rates. We used this method to estimate the following parameters: speciation and extinction rates $\lambda_{0}$ and $\mu_{0}$ of nonred lineages and $\lambda_{1}$ and $\mu_{1}$ of red lineages and two transition rates representing the evolution of red flowers $\left(q_{01}\right)$ and the backwards transitions of evolving nonred flowers $\left(q_{10}\right)$, and then compute the likelihood of character states at the tips of our phylogenetic tree, given the maximum likelihood values of speciation, extinction and transition rates (the unconstrained model) [37]. We then constrain certain parameters to be equal to each other and test alternative models of evolution against the unconstrained model with likelihood ratio tests. We examined the fit of a model with (1) equal speciation rates $\left(\lambda_{1}=\lambda_{0}\right)$, one with equal extinction rates $\left(\mu_{1}=\mu_{0}\right)$, one with equal speciation and extinction rates $\left(\lambda_{1}=\lambda_{0}\right.$ and $\left.\mu_{1}=\mu_{0}\right)$, and, finally, one with equal transition/migration rates $\left(q_{10}=q_{01}\right)$.

We further formalize ancestral reconstructions in Mesquite version 2.75 [28] to characterize the evolutionary history of Mimulus. We first used unordered maximum parsimony (MP) reconstruction for standard categorical data. For the second analysis, we performed ML reconstruction with Markov $k$-state 1 model for standard categorical data. MCC tree obtained from the Bayesian analysis with combined DNA sequence data is used for both ancestral reconstructions. Red (or reddish) floral colour is denoted as 1 , and all the other floral colours are denoted as 0 in the character matrix. Finally, we established whether the origins of floral colour coincided with entry into specific biogeographical origins using Reconstruct Ancestral State in Phylogenies (RASP) version 2.1 beta [40] software. Three alternative reconstruction methods were used: (1) Statistical Dispersal-Vicariance Analysis [41], (2) Bayesian binary method [42], and (3) dispersalextinction-cladogenesis model [43]. Four discrete states were used for present-day continental geographical distribution: North America, South America, Asia, and Oceania (Table 2). Analyses were conducted on the maximum clade credibility tree generated on BEAST using combined sequence data, and the results were summarized as tree graphs and pie charts.

2.3.2. Diversification at Different Elevations. The GeoSSE functions within "diversitree" can be used to test differential speciation and extinction within different geographical regions as well as the speciation that might accompany range shifts. We implemented GeoSSE within "diversitree" to examine whether clades at high-elevation bands experienced greater speciation. The framework is very similar, but the parameters are speciation within low elevation regions (with range restricted to $<1000 \mathrm{~m}$; sA), speciation within high elevation regions (with range restricted to $>1000 \mathrm{~m}$, $\mathrm{sB}$ ), between-region speciation ( $\mathrm{sAB}$ ), extinction from low elevation regions $(\mathrm{xA})$, extinction from high elevation regions $(\mathrm{xB})$, dispersal from $\mathrm{A}$ to $\mathrm{B}$ (range expansion, $\mathrm{dA}$ ), and dispersal from $B$ to $A(d B)$. We coded the species in three categories: $\mathrm{A}=$ restricted to low elevations, $\mathrm{B}=$ restricted to high elevations, and $\mathrm{AB}=$ ranges that span low and high elevation. By setting certain constraints we can test for whether speciation, extinction, or range expansion is different between regions. We also examine the variation in the estimates of these rates with Markov models.

2.3.3. Correlations between Red(dish) Flowers and High Elevations. A final analysis, MuSSE, was run to test whether red flowers are correlated with high elevation zones. In the MuSSE analysis, trait combinations use the following notation: 1: low elevation, no-RO; 2: low elevation, RO; 3: high elevation, no-RO; 4: high elevation, RO. We test whether the evolution of the RO phenotype depends on the background of elevation (does $1 \rightarrow 2$ differ from $3 \rightarrow 4$ or $1 \rightarrow 3$ from $2 \rightarrow 4$, etc.) by constraining transition rates $\left(q_{12}=q_{34}\right.$, $q_{13}=q_{24}, q_{21}=q_{43}$, and $\left.q_{31}=q_{42}\right)$ and comparing the likelihood of the tip character states on our phylogeny with log-likelihood tests.

\section{Results}

3.1. Data Set. We provide the compiled traits of Mimulus species in Table 2 . We were able to obtain high sampling of sequence data for Mimulus, covering 94 of the $\sim 120$ species ( $\sim 79 \%$ of the species were included in our analysis). As well, we had unbiased covering of the species in Mimulus; $10.6 \%$ of the species in our phylogeny are RO, identical to the approximately $10.6 \%$ in the genus as a whole that we estimate to be RO (see Table 2).

We had two nuclear markers: ETS and ITS with sequence data for 90 and 91 taxa for these markers, respectively. After the alignment of all the taxa, the total length of the ETS and ITS regions analyzed was 477 and $688 \mathrm{bp}$, respectively. For the chloroplast marker $t r n L-F$, we had sequence data for 85 taxa. Once all the taxa were aligned, the analyzed trnL$F$ region was 1122 bp long. When we align and combine all three markers (two nuclear and one chloroplast) together, the resulting matrix contained 2287 characters, comprising 94 taxa excluding the outgroup.

3.2. Mimulus Phylogeny. ML and Bayesian analyses of the individual DNA markers resulted in largely congruent topologies for the genus Mimulus (data not shown). When we compare individual marker data with the combined sequence data, combined molecular analysis provided higher resolution and more consistent tree topologies. We used partitioned and nonpartitioned combined data for ML analyses, and they both provided the same tree topology with 


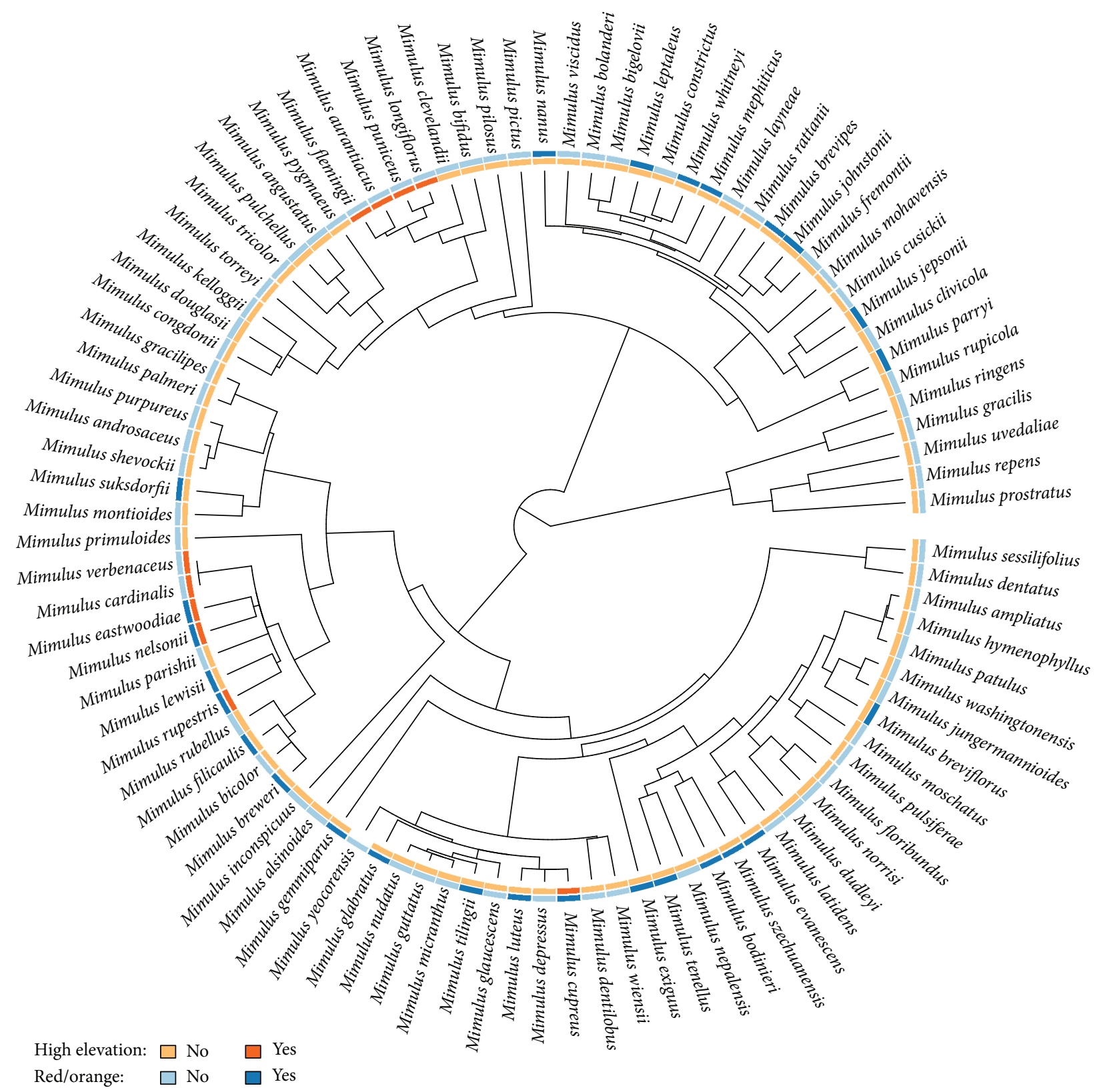

FIGURE 1: Ultrametric phylogeny of Mimulus with red/orange (RO) and restriction to high elevation (blue shading) mapped onto the tips.

slightly different likelihood values (data shown only for nonpartitioned analysis). Therefore we used nonpartitioned ML tree for further analyses. Overall, for the combined DNA sequence data, MCC tree from the Bayesian analysis is largely congruent with the ML analysis (Figure 1), with the Bayesian tree having higher resolution (see Supplementary Figure 1 in the Supplementary Material available online at http://dx.doi.org/10.1155/2014/382453, Supplementary Figure 2). Overall, the phylogeny inferred for Mimulus is very similar to the previously published phylogenies using alternative sampling and methods [17-20,44].

3.3. Ancestral Reconstruction. All three biogeographical origin reconstruction methods show strong support (93.83\%) for the North American origin for the genus Mimulus (see Supplementary Figure 3 for Bayesian Binary MCMC Analysis). Both ML and Bayesian analyses highly supported the clade with Oceanic distribution consisting $M$. prostratus, $M$. repens, $M$. uvedaliae, and $M$. gracilis, with bootstrap value (BS) of $100 \%$ and posterior probability (PP) of 1.0. North American taxon; $M$. ringens is also nested in this clade. Bayesian binary MCMC analysis remains inconclusive with respect to the origin of this clade. There is high support for the Oceania origin for $M$. prostratus, $M$. repens, and $M$. uvedaliae (PP: 98.53\%), but PP values are not decisive with respect to the origin of the whole clade (45.58\%: Oceania origin, $30.35 \%$ : North America origin). Highly supported clade consisting of M. tenellus, M. nepalensis, M. szechuanensis, and M. bodinieri 


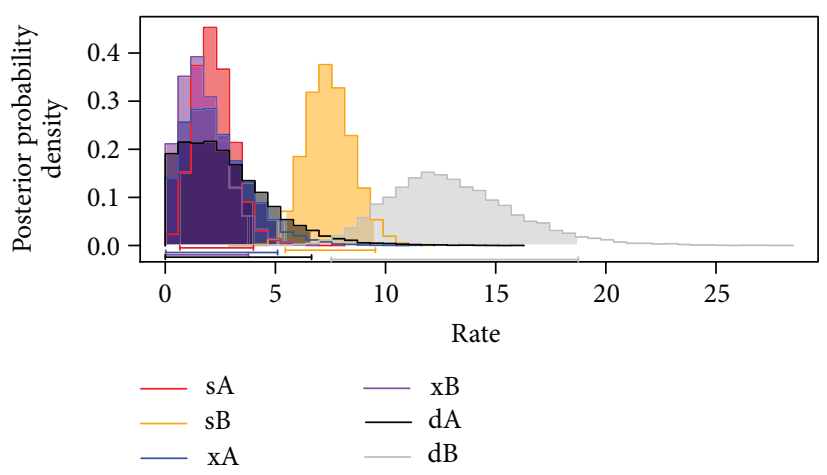

(a)

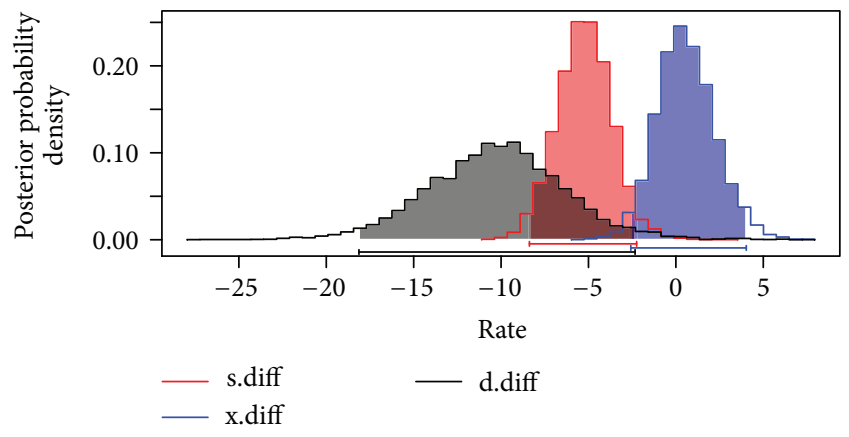

(b)

FIGURE 2: Posterior probability distributions for the six-rate GeoSSE model for the tree shown in Figure 1. (a) The parameters are speciation within low elevation regions (sA), speciation within high elevation regions (sB), and between-region speciation. (sAB), extinction from low elevation regions (xA) extinction from high elevation regions. (xB), dispersal from A to B (range expansion, $\mathrm{dA}$ ) and dispersal from $\mathrm{B}$ to $\mathrm{A}$ $(\mathrm{dB})$. Differences in dispersal are greater for range expansion from B (high elevation) to A (b) yet higher speciation rates in high elevation environments can still be observed.

is found in both ML and Bayesian analyses (BS: 92\%, PP: 1.0). Bayesian Binary MCMC analysis of biogeographic origin strongly suggests an Asian origin for this clade (PP: 93.58\%). Another species with Asian distribution, M. sessiflorus, is not clustered with the rest of the Asian taxa in either ML or Bayesian analysis, and the position of this species is poorly resolved in both trees. $M$. depressus, $M$. cupreus, and $M$. luteus form a strongly supported clade in both ML and Bayesian analyses (BS: 97\%, PP: 1.0). For this clade, a South American origin was suggested by Bayesian MCMC analysis of biogeographic origin (PP: 82.67\%). An alternative to a South American origin, the clade might also have originated in the Americas (North and South America together), but the PP values are too weak to support this view (PP: 13.40\%).

Both MP and ML analysis showed that the ancestor of the genus Mimulus was unlikely to have reddish flowers. Likelihood values for 1 (reddish) is 0.02 and for 0 (not reddish) is 0.98 . Out of 95 Mimulus species, 14 of them have RO flowers. There are 2 major clades with RO flowers: M. bifidus, M. flemingii, M. aurantiacus, M. longiflorus, $M$. puniceus (RO), and M. clevelandii (not RO) form one of the red clades, with a potential RO-flowered common ancestor (1: $0.622,0: 0.378)$. The other clade with a potential RO-flowered ancestor includes the species $M$. rupestris, $M$. cardinalis, $M$. verbenaceus, $M$. eastwoodiae, and $M$. nelsonii (RO) and $M$. lewisii, and M. parishii (not RO) (1: 0.628, 0: 0.372). According to our ancestral reconstruction analysis, all the RO flowered Mimulus taxa have appeared later than $20 \mathrm{Ma}$, which is intriguingly consistent with the approximate time for the hummingbird origins in the Americas [45].

\subsection{Phylogenetic Comparative Analysis}

3.4.1. Differential Diversification with Differing Floral Colours. We find that specialization, measured narrowly as having the trait state of "reddish" flowers, is not associated with higher speciation rates (Table 1; $P=0.196$ ). However, the rate of transition to the trait state of "reddish flowers" (i.e., the ability to evolve red flowers) is different from the rate at which a lineage transitions away from "reddish flowers" (Table 1; $P=0.02895)$; that is, losing red coloration happens far more frequently than gaining it. Finally, we could not find any evidence suggesting that clades with "reddish" flowers experience differential extinction rates than those without "reddish" flowers $(P=0.7996)$.

3.4.2. Differential Diversification at Different Elevations. Parameters from our GeoSSE analysis are provided in Table 1. In Mimulus, we can reject the model of equal speciation and extinction at different elevational bands, concluding that high elevation regions experience increases in diversification (Figure 2; $P=0.002$ ). With this being an intriguing, yet somewhat surprising result, we reran the analyses with a small subset of bootstrap trees and found the result to be robust to phylogenetic uncertainty $(P$ values ranging from 0.002 to $<0.0001, N=10$ ). Including the between-region mode of speciation does not, however, significantly improve the fit $(P=1.00)$. We also find that high elevation lineages experience increased range expansion into lower elevations more so than the reverse (Figure 2; $P=0.02$ ).

3.4.3. Correlated Transitions between Red Flowers and High Elevations. We provide maximum likelihood parameters from our MuSSE analysis in Table 1. Our MuSSE analysis tested whether certain transitions were more common than others (e.g., we can test if RO flowers evolve more often in high elevation environments), yet we did not find any evidence that these transition rates were unequal $(P=$ 0.21 ) in such a way that would result in a disproportionate number of RO-flowered species in high elevation locations (see Figure 1).

\section{Discussion}

We hypothesized that red flowered lineages might be restricted to high elevation environments as others have 
TABLE 1: Results of BiSSE, GeoSSE, and MuSSE analyses of RO phenotype and high elevation in Mimulus. In the BiSSE/GeoSSE analysis, we use the notation of non- $\mathrm{RO}=0$ and $\mathrm{RO}=1$, low elevation $=0$, and high elevation $=1$ (and the GeoSSE analysis allows for third category for species having ranges that span low and high elevation). In the MuSSE analysis, trait combinations use the following notation: 1: low elevation, no-RO; 2: low elevation, RO; 3: high elevation, no-RO; 4: high elevation, RO. We test whether the evolution of the RO phenotype depends on the background of elevation (does $1 \rightarrow 2$ differ from $3 \rightarrow 4$ or $1 \rightarrow 3$ from $2 \rightarrow 4$, etc.). ${ }^{*} P<0.05$ and $^{* *}<0.001$.

\begin{tabular}{lcc}
\hline Model & $\operatorname{lnLik}$ & AIC \\
\hline $\begin{array}{l}\text { Differential diversification of red-flowered } \\
\text { lineages }\end{array}$ & & \\
Full model $\left(\lambda_{0}=6.88 ; \lambda_{1}=12.76 ; \mu_{0}=0 ;\right.$ & 70.21 & -128.42 \\
$\left.\mu_{1}=3.3 ; q_{01}=0.42 ; q_{10}=5.36\right)$ & 69.37 & -128.75 \\
$\lambda_{1}=\lambda_{0}$ & 70.18 & -130.35 \\
$\mu_{1}=\mu_{0}$ & $67.82^{*}$ & -125.65 \\
$q_{10}=q_{01}$ & & \\
Differential diversification of high elevation & & \\
lineages & & \\
Full model $\left(\lambda_{0}=0.72 ; \lambda_{1}=9.69 ; \lambda_{01}=0 ;\right.$ & -10.05 & 34.09 \\
$\left.\mu_{0}=16.13 ; \mu_{1}=5.08 ; d_{01}=0 ; d_{10}=45.46\right)$ & & \\
$\lambda_{01}=0($ between-region mode of & -10.05 & 32.09 \\
speciation $)$ & $-16.19^{* *}$ & 42.37 \\
$\lambda_{1}=\lambda_{0}$ & $-13.22^{*}$ & 38.44 \\
$d_{10}=d_{01}$ & & \\
Correlated evolution of red flowers and high & & \\
elevation & & \\
Full model $\left(\lambda=7.20 ; \mu=0.00 ; q_{12}=0.101 ;\right.$ & & \\
$q_{34}=0.997 ; q_{21}=2.301 ; q_{43}=7.208 ;$ & & \\
$q_{13}=8.157 ; q_{24}=-8.157 ; q_{31}=2.350 ;$ & & \\
$\left.q_{42}=-2.179\right)$ & & \\
$q_{12}=q_{34}, q_{13}=q_{24}, q_{21}=q_{43}, q_{31}=q_{42}$ & 17.51 & \\
\hline
\end{tabular}

posited [15] and that this might contribute to lower speciation rates. Surprisingly, we found no indication that red flowered species are more prevalent at high elevation, yet high elevation bands were actually regions of increased speciation. In addition, we found no indication that speciation accompanied shifts between elevational zones. Previous studies have also found that diversification rates increase in mountainous regions $[10,46]$ and our study in Mimulus corroborates these findings.

Finally, the species that originate in high elevation environments show an increased propensity to experience range expansion into low elevation environments, supporting other studies that suggest that the increased diversification of alpine regions provides a "species pump" for global species richness $[46,47]$.

Floral colour can be considered as a secondary sexual characteristic in flowering plants, somewhat analogous to exaggerated ornaments in animals [48]. Because floral colour provides an important cue for pollinators, differences in colour can translate to attracting an increased number of visits from efficient pollinators, which often results in increased pollen transfer [49] and a reduction in the amount of inbreeding [50]. Reddish flowers are typically associated with pollination by birds [51], though this relationship is far from absolute. In Mimulus, a primarily North American lineage, bird pollination is almost exclusively hummingbird pollination. While hummingbird pollination is thought to be an extremely efficient means of dispersing pollen and evolving reddish flowers may be an adaptation for bird pollination, we did not find that the evolution or red/orange flowers was associated with increased speciation rates or decreased extinction rates, and the character state appears to be more ephemeral than a non-RO phenotype. Also, RO lineages were not restricted to high elevation environments as has been supposed [15], yet we find that high elevation environments were hotspots for speciation, possibly due to the topographical heterogeneity presented by isolated mountain peaks [10].

Potential reasons for the increased transition rates away from the RO phenotype involve scenarios that incorporate the ease at which a mutant can arise and the probability that such a mutation can fix. One scenario that might be included is that the flowers themselves are costly (red-hued flowers are associated with hummingbird pollination and these flowers might also be large and nectar rich), and so the phenotype is only selected in environments where other pollinators (e.g., bees) are scarce. Furthermore, there are many nonpollinator agents of selection as well as genetic arguments that may be responsible for this pattern and the ease of transitions away from an $\mathrm{RO}$ phenotype is not devoid of empirical evidence. Yellow morphs have been observed to be easily established in more than one population of Mimulus cardinalis [52]. While transitions from blue to red have been observed to be more common than the reverse [16], there has been little work done on the transitions between red and yellow flowers (the most common alternate floral colour in Mimulus). Transitions from pigmented to nonpigmented flowers are thought to be more common than the reverse generally [16], and the agents of selection may or may not include pollinators [53]. Phylogenetic comparisons in Ipomoea revealed that transition rates between the two character states were roughly equal but nonpigmented flowers had lower speciation rates [54]. White flowers are potentially an adaptation for moth pollination [55], yet might also be selectively favoured if the resources for costly pigments can be coopted for other functions. Because Mimulus includes few nonpigmented (white) flowered species, direct comparisons with previous studies are difficult because yellow flowers still contain flavonol pigments.

Another potential explanation to why transitions to red flowers are rare in Mimulus could be that the hummingbird family (a potential selective agent) originated about 20 mya [45], which is relatively recent when compared to the history of Mimulus. In other words, the ecological opportunity for adapting to the hummingbird pollination syndrome was not a possible transition for much of the tree space we analyzed in Mimulus [56]. Further studies on pollination syndromes that examine transition rates (and speciation rates) before and after the origins of hummingbirds with direct observations of pollinator visitation rates might be able to refine the role that the origin of a new mutualist has had on North American angiosperm genera. 
TABLE 2: Elevation ranges, geographical distribution, and qualitative assessments of floral colour, as well as Genbank accession numbers for the species of Mimulus used in this study.

\begin{tabular}{|c|c|c|c|c|c|c|}
\hline Species & Color & Dist. & Elev. $(\mathrm{m})$ & ETS & ITS & $\operatorname{trnL}-\mathrm{F}$ \\
\hline Mimulus alsinoides & Yellow & N. America & $0-860$ & AY575340.1 & AY575450.1 & AY575542.1 \\
\hline Mimulus ampliatus & Yellow & N. America & $610-1067$ & AY575310.1 & AY575421.1 & AY575517.1 \\
\hline Mimulus androsaceus & Purple & N. America & $0-1219$ & - & AY575400.1 & AY575502.1 \\
\hline Mimulus angustatus & White, yellow, and pink/purple & N. America & $0-1219$ & AY575269.1 & AY575378.1 & AY575485.1 \\
\hline Mimulus aurantiacus & Red/orange & N. America & $0-2286$ & AF478950.1 & AF478917.1 & AF478982.1 \\
\hline Mimulus bicolor & Yellow and white & N. America & $0-1829$ & AY575298.1 & AY575409.1 & AF478995.1 \\
\hline Mimulus bifidus & White/orange/yellow & N. America & $0-1524$ & AY575283.1 & AY575391.1 & AY575496.1 \\
\hline Mimulus bigelovii & Pink/purple & N. America & $120-2300$ & AY575242.1 & AY575353.1 & AY575461.1 \\
\hline Mimulus bodinieri & - & Asia & - & AY575323.1 & AY575434.1 & - \\
\hline Mimulus bolanderi & Pink/purple & N. America & 0-1981 & AY575241.1 & AY575352.1 & AY575460.1 \\
\hline Mimulus breviflorus & Yellow & N. America & $1450-2200$ & AY575314.1 & AY575425.1 & AY575521.1 \\
\hline Mimulus brevipes & Yellow & N. America & $1524-2164$ & AY575247.1 & AY575358.1 & AY575466.1 \\
\hline Mimulus breweri & Pink/purple & N. America & $1219-3353$ & - & - & AY575509.1 \\
\hline Mimulus cardinalis & Red & N. America & $0-2438$ & AF478964.1 & AY575414.1 & AF478996.1 \\
\hline Mimulus clevelandii & Yellow & N. America & $915-1465$ & AY575278.1 & AY575386.1 & AF478983.1 \\
\hline Mimulus clivicola & Pink & N. America & $488-1250$ & AY575258.1 & AY575369.1 & AY575477.1 \\
\hline Mimulus congdonii & Pink/purple & N. America & $0-914$ & AY575275.1 & AY575383.1 & AY575489.1 \\
\hline Mimulus constrictus & Pink/purple & N. America & $750-2200$ & AY575238.1 & AY575349.1 & AY575457.1 \\
\hline Mimulus cupreus & Red/orange & S. America & 2300 & AY575336.1 & AY575447.1 & AY575540.1 \\
\hline Mimulus cusickii & Pink/purple & N. America & $600-1600$ & AY575256.1 & AY575367.1 & AY575475.1 \\
\hline Mimulus dentatus & Yellow & N. America & $0-397$ & AY575338.1 & AY575449.1 & - \\
\hline Mimulus dentilobus & Yellow & N. America & - & AY575333.1 & AY575444.1 & AY575537.1 \\
\hline Mimulus depressus & Yellow & S. America & $0-1158$ & AF478961.1 & AY575446.1 & AY575539.1 \\
\hline Mimulus douglasii & Pink/purple & N. America & $0-1219$ & AY575273.1 & AY575381.1 & AF478984.1 \\
\hline Mimulus dudleyi & Yellow & N. America & Lower elevations & AY575321.1 & AY575432.1 & AY575528.1 \\
\hline Mimulus eastwoodiae & Red & N. America & $1433-1768$ & AY575306.1 & AY575417.1 & - \\
\hline Mimulus evanescens & Yellow & N. America & $1250-1700$ & AY575347.1 & AY575455.1 & AY575547.1 \\
\hline Mimulus exiguus & Pink/purple & N. America & 1640 & AY575309.1 & AY575420.1 & AY575516.1 \\
\hline Mimulus filicaulis & Pink/purple & N. America & $1219-1524$ & AY575299.1 & AY575410.1 & AY575511.1 \\
\hline Mimulus flemingii & Red/orange & N. America & - & AY575287.1 & AY575395.1 & AY575499.1 \\
\hline Mimulus floribundus & Yellow & N. America & $0-3353$ & AF478959.1 & AF478926.1 & AF478991.1 \\
\hline Mimulus fremontii & Pink/purple & N. America & $75-2100$ & AY575246.1 & AY575357.1 & AY575465.1 \\
\hline Mimulus gemmiparus & Yellow & N. America & Higher elevations & AY575341.1 & AY575451.1 & AY575543.1 \\
\hline Mimulus glabratus & Yellow & N. America & $1800-3200$ & AY575334.1 & AY575445.1 & AY575538.1 \\
\hline Mimulus glaucescens & Yellow & N. America & $0-762$ & AY575332.1 & AY575443.1 & AY575536.1 \\
\hline Mimulus gracilipes & Pink/purple & N. America & - & AY575296.1 & AY575407.1 & AY575508.1 \\
\hline Mimulus gracilis & Purple & Oceania & $250-1530$ & AY575345.1 & AF478934.1 & AF478999.1 \\
\hline Mimulus guttatus & Yellow & N. America & $0-3048$ & AY575328.1 & AY575439.1 & AY575533.1 \\
\hline Mimulus hymenophyllus & Yellow & N. America & 1086 & AY575311.1 & AY575422.1 & AY575518.1 \\
\hline Mimulus inconspicuus & Pink/purple & N. America & $0-2896$ & AY575342.1 & AY575452.1 & AY575544.1 \\
\hline Mimulus jepsonii & Pink/purple & N. America & $1219-2743$ & AY575259.1 & AY575370.1 & AY575478.1 \\
\hline Mimulus johnstonii & Pink/purple & N. America & $1219-2134$ & AY575248.1 & AY575359.1 & AY575467.1 \\
\hline Mimulus jungermannioides & Yellow & N. America & $152-1006$ & AY575315.1 & AY575426.1 & AY575522.1 \\
\hline Mimulus kelloggii & Pink/purple & N. America & $0-914$ & AY575274.1 & AY575382.1 & AY575488.1 \\
\hline Mimulus latidens & Light pink & N. America & $0-762$ & AY575318.1 & AY575429.1 & AY575525.1 \\
\hline Mimulus layneae & Pink & N. America & $0-2286$ & AY575260.1 & AY575371.1 & AY575479.1 \\
\hline Mimulus leptaleus & Pink/purple & N. America & $1950-3353$ & AY575239.1 & AY575350.1 & AY575458.1 \\
\hline Mimulus lewisii & Pink & N. America & 1219-3048 & AF478965.1 & AF478932.1 & AF478997.1 \\
\hline Mimulus longiflorus & Red/orange & N. America & $0-2286$ & AY575285.1 & AY575393.1 & AY575498.1 \\
\hline
\end{tabular}


TABLE 2: Continued.

\begin{tabular}{|c|c|c|c|c|c|c|}
\hline Species & Color & Dist. & Elev. (m) & ETS & ITS & trnL-F \\
\hline Mimulus luteus & Yellow & S. America & $1400-2900$ & AY575337.1 & AY575448.1 & AY575541.1 \\
\hline Mimulus mephiticus & Pink & N. America & $1219-3658$ & AY575244.1 & AY575355.1 & AY575463.1 \\
\hline Mimulus micranthus & Yellow & N. America & & AY575329.1 & AY575440.1 & AY575534.1 \\
\hline Mimulus mohavensis & White and pink & N. America & $600-1200$ & AY575264.1 & AY575375.1 & AY575482.1 \\
\hline Mimulus montioides & Yellow & N. America & $914-5553$ & AY575294.1 & AY575405.1 & AY575506.1 \\
\hline Mimulus moschatus & Yellow & N. America & $0-2682$ & AY575317.1 & AY575428.1 & AY575524.1 \\
\hline Mimulus nanus & Pink/purple & N. America & $1372-2286$ & AY575249.1 & AY575360.1 & AY575468.1 \\
\hline Mimulus nelsonii & Red & N. America & $2438-2743$ & AY575302.1 & AY575413.1 & - \\
\hline Mimulus nepalensis & Yellow & Asia & $0-867$ & AY575324.1 & AY575435.1 & AY575530.1 \\
\hline Mimulus norrisi & Yellow & N. America & - & AY575322.1 & AY575433.1 & AY575529.1 \\
\hline Mimulus nudatus & Yellow & N. America & $250-700$ & AY575330.1 & AY575441.1 & AY575535.1 \\
\hline Mimulus palmeri & Pink & N. America & $0-2134$ & AY575295.1 & AY575406.1 & AY575507.1 \\
\hline Mimulus parishii & Light pink & N. America & $0-2100$ & AY575300.1 & AY575411.1 & AY575512.1 \\
\hline Mimulus parryi & Pink/purple & N. America & $1200-2600$ & AY575277.1 & AY575385.1 & AY575491.1 \\
\hline Mimulus patulus & Yellow & N. America & $305-610$ & AY575312.1 & AY575423.1 & AY575519.1 \\
\hline Mimulus pictus & Purple and white & N. America & $305-1219$ & AY575265.1 & AY575376.1 & AY575483.1 \\
\hline Mimulus pilosus & Yellow & N. America & $0-2591$ & AY575266.1 & - & - \\
\hline Mimulus primuloides & Yellow & N. America & $600-3414$ & AY575308.1 & AY575419.1 & AY575515.1 \\
\hline Mimulus prostratus & Purple and white & Oceania & - & AY943099.1 & AY943125.1 & AY943150.1 \\
\hline Mimulus pulchellus & Yellow and pink/purple & N. America & $914-1524$ & AF478953.1 & AF478920.1 & AF478985.1 \\
\hline Mimulus pulsiferae & Yellow & N. America & $762-1524$ & AY575313.1 & AY575424.1 & AY575520.1 \\
\hline Mimulus puniceus & Red/orange & N. America & - & AY575279.1 & AY575387.1 & AY575493.1 \\
\hline Mimulus purpureus & Purple & N. America & Lower elevations & - & AY575402.1 & AY575504.1 \\
\hline Mimulus pygmaeus & Yellow & N. America & $500-1840$ & AY575272.1 & - & - \\
\hline Mimulus rattanii & Pink/purple & N. America & 260 & AY575245.1 & AY575356.1 & AY575464.1 \\
\hline Mimulus repens & Purple & Oceania & 45 & AY943088.1 & AY943115.1 & - \\
\hline Mimulus ringens & Purple & N. America & $0-200$ & AY575344.1 & AY575454.1 & AF479000.1 \\
\hline Mimulus rubellus & Pink & N. America & $800-3600$ & AY575297.1 & AY575408.1 & AY575510.1 \\
\hline Mimulus rupestris & Red & N. America & 2286 & AY575301.1 & AY575412.1 & AY575513.1 \\
\hline Mimulus rupicola & Light pink/purple & N. America & $305-1798$ & AY575276.1 & AY575384.1 & AY575490.1 \\
\hline Mimulus sessilifolius & Yellow & Asia & $0-2707$ & AY575339.1 & - & - \\
\hline Mimulus shevockii & Yellow & N. America & $823-1341$ & - & AY575403.1 & AY575505.1 \\
\hline Mimulus suksdorfii & Yellow & N. America & $1524-3962$ & AY575292.1 & AY575401.1 & AY575503.1 \\
\hline Mimulus szechuanensis & Yellow & Asla & - & - & FJ172743.1 & FJ172692.1 \\
\hline Mimulus tenellus & Yellow & Asia & $0-3048$ & AY575325.1 & AY575436.1 & FJ172691.1 \\
\hline Mimulus tilingii & Yellow & N. America & $1950-3658$ & AY575330.1 & AY575442.1 & AF478994.1 \\
\hline Mimulus torreyi & Pink/purple & N. America & $0-2438$ & AY575262.1 & AY575373.1 & AY575481.1 \\
\hline Mimulus tricolor & White, yellow and pink/purple & N. America & $0-610$ & AY575268.1 & AY575377.1 & AY575484.1 \\
\hline Mimulus uvedaliae & Purple and white & Oceania & - & AY575346.1 & AF478936.1 & AF479001.1 \\
\hline Mimulus verbenaceus & Red & N. America & $985-1676$ & AY575307.1 & AY575418.1 & - \\
\hline Mimulus viscidus & White and pink/red & N. America & $610-1829$ & AY575243.1 & AY575354.1 & AY575462.1 \\
\hline Mimulus washingtonensis & Yellow & N. America & - & AY575316.1 & AY575427.1 & AY575523.1 \\
\hline Mimulus whitneyi & Pink or yellow & N. America & $1829-3353$ & AY575237.1 & AY575348.1 & AY575456.1 \\
\hline Mimulus wiensii & - & N. America & $678-797$ & AY575326.1 & AY575437.1 & AY575531.1 \\
\hline Mimulus yeocorensis & - & N. America & - & AY575327.1 & AY575438.1 & AY575532.1 \\
\hline Mohavea breviflora & & & & AF478979.1 & AF513892.1 & AF479011.1 \\
\hline
\end{tabular}




\section{Conflict of Interests}

There is no conflict of interests regarding the publication of this paper.

\section{Acknowledgments}

The authors thank S. Otto for help with "diversitree”. Funding for the project was provided to Jana C. Vamosi from an NSERC Discovery Grant and CANPOLIN. This is publication no. 107 of CANPOLIN.

\section{References}

[1] B. Igic, R. Lande, and J. R. Kohn, "Loss of self-incompatibility and its evolutionary consequences," International Journal of Plant Sciences, vol. 169, no. 1, pp. 93-104, 2008.

[2] R. D. Sargent, "Floral symmetry affects speciation rates in angiosperms," Proceedings of the Royal Society B, vol. 271, no. 1539, pp. 603-608, 2004.

[3] R. E. Ricklefs, "History and diversity: explorations at the intersection of ecology and evolution," American Naturalist, vol. 170, pp. S56-S70, 2007.

[4] D. L. Rabosky, "Ecological limits and diversification rate: alternative paradigms to explain the variation in species richness among clades and regions," Ecology Letters, vol. 12, no. 8, pp. 735-743, 2009.

[5] J. C. Vamosi and S. M. Vamosi, "Key innovations within a geographical context in flowering plants: towards resolving Darwin's abominable mystery," Ecology Letters, vol. 13, no. 10, pp. 1270-1279, 2010.

[6] S. M. Vamosi and J. C. Vamosi, "Causes and consequences of range size variation: the influence of traits, speciation, and extinction," Frontiers of Biogeography, vol. 4, no. 4, 2012.

[7] I. P. F. Owens, P. M. Bennett, and P. H. Harvey, "Species richness among birds: body size, life history, sexual selection or ecology?" Proceedings of the Royal Society B, vol. 266, no. 1422, pp. 933-939, 1999.

[8] K. Böhning-Gaese, T. Caprano, K. van Ewijk, and M. Veith, "Range size: disentangling current traits and phylogenetic and biogeographic factors," American Naturalist, vol. 167, no. 4, pp. 555-567, 2006.

[9] J. B. Losos and D. Schluter, "Analysis of an evolutionary speciesarea relationship," Nature, vol. 408, no. 6814, pp. 847-850, 2000.

[10] C. Hughes and R. Eastwood, "Island radiation on a continental scale: exceptional rates of plant diversification after uplift of the Andes," Proceedings of the National Academy of Sciences of the United States of America, vol. 103, no. 27, pp. 10334-10339, 2006.

[11] W. S. Armbruster, "Can indirect selection and genetic context contribute to trait diversification? A transition-probability study of blossom-colour evolution in two genera," Journal of Evolutionary Biology, vol. 15, no. 3, pp. 468-486, 2002.

[12] S. E. J. Arnold, V. Savolainen, and L. Chittka, "Flower colours along an alpine altitude gradient, seen through the eyes of fly and bee pollinators," Arthropod-Plant Interactions, vol. 3, no. 1, pp. 27-43, 2009.

[13] L. van der Pijl, "Reproductive integration and sexual disharmony in floral functions," in The Pollination of Flowers By Insects, A. J. Richards, Ed., pp. 79-88, Academic Press, London, UK, 1978.
[14] J. Ollerton, R. Alarcón, N. M. Waser et al., "A global test of the pollination syndrome hypothesis," Annals of Botany, vol. 103, no. 9, pp. 1471-1480, 2009.

[15] R. W. Cruden, "Pollinators in high-elevation ecosystems: relative effectiveness of birds and bees," Science, vol. 176, no. 4042, pp. 1439-1440, 1972.

[16] M. D. Rausher, "Evolutionary transitions in floral color," International Journal of Plant Sciences, vol. 169, no. 1, pp. 7-21, 2008.

[17] D. L. Grossenbacher and J. B. Whittall, "Increased floral divergence in sympatric monkeyflowers," Evolution, vol. 65, no. 9, pp. 2712-2718, 2011.

[18] P. M. Beardsley, S. E. Schoenig, J. B. Whittall, and R. G. Olmstead, "Patterns of evolution in western North American Mimulus (Phrymaceae)," American Journal of Botany, vol. 91, no. 3, pp. 474-489, 2004.

[19] J. B. Whittall, M. L. Carlson, P. M. Beardsley, R. J. Meinke, and A. Liston, "The Mimulus moschatus alliance (Phrymaceae): molecular and morphological phylogenetics and their conservation implications," Systematic Botany, vol. 31, no. 2, pp. 380397, 2006.

[20] P. M. Beardsley and R. G. Olmstead, "Redefining phrymaceae: the placement of Mimulus, tribe mimuleae, and Phryma," American Journal of Botany, vol. 89, no. 7, pp. 1093-1102, 2002.

[21] California Native Plant Society (CNPS), "Inventory of Rare and Endangered Plants," California Native Plant Society, Sacramento, Calif, USA, June 2013.

[22] Calflora, "Information on California plants for education, research and conservation," The Calflora Database, Berkeley, Calif, USA, 2014.

[23] EOL, "Encyclopedia of Life," 2013, http://eol.org/.

[24] J. F. Project, Ed., Jepson, June 2013, http://ucjeps.berkeley.edu/ IJM.html.

[25] FloraBase and Western Australian Herbarium (1998-2013), "FloraBase-the Western Australian Flora," Department of Parks and Wildlife, 2013, http://florabase.dpaw.wa.gov.au/.

[26] USDA, NRCS, The PLANTS Database, National Plant Data Team, Greensboro, NC, USA, 27401-4901 USA, 2010, http:// plants.usda.gov/java/.

[27] R. G. Olmstead, C. W. Depamphilis, A. D. Wolfe, N. D. Young, W. J. Elisons, and P. A. Reeves, "Disintegration of the scrophulariaceae," American Journal of Botany, vol. 88, no. 2, pp. 348361, 2001.

[28] W. P. Maddison and D. R. Maddison, "Mesquite: a modular system for evolutionary analysis," Version 2.75, 2011, http://mesquiteproject.org/mesquite/mesquite.html.

[29] T. J. Wheeler and J. D. Kececioglu, "Multiple alignment by aligning alignments," Bioinformatics, vol. 23, no. 13, pp. i559-i568, 2007.

[30] A. Stamatakis, "RAxML-VI-HPC: maximum likelihood-based phylogenetic analyses with thousands of taxa and mixed models," Bioinformatics, vol. 22, no. 21, pp. 2688-2690, 2006.

[31] A. J. Drummond and A. Rambaut, "BEAST: bayesian evolutionary analysis by sampling trees," BMC Evolutionary Biology, vol. 7, no. 1, article 214, 2007.

[32] A. J. Drummond, M. A. Suchard, D. Xie, and A. Rambaut, "Bayesian phylogenetics with BEAUti and the BEAST 1.7," Molecular Biology and Evolution, vol. 29, pp. 1969-1973, 2012.

[33] M. Hasegawa, H. Kishino, and T. Yano, "Dating of the humanape splitting by a molecular clock of mitochondrial DNA," Journal of Molecular Evolution, vol. 22, no. 2, pp. 160-174, 1985. 
[34] K. Bremer, E. M. Friis, and B. Bremer, "Molecular phylogenetic dating of asterid flowering plants shows early cretaceous diversification," Systematic Biology, vol. 53, no. 3, pp. 496-505, 2004.

[35] T. Gernhard, “The conditioned reconstructed process," Journal of Theoretical Biology, vol. 253, no. 4, pp. 769-778, 2008.

[36] G. U. Yule, "A mathematical theory of evolution based on the conclusions of Dr. J.C. Willis," Philosophical Transactions of the Royal Society B, vol. 213, pp. 21-87, 1925.

[37] W. P. Maddison, P. E. Midford, and S. P. Otto, "Estimating a binary character's effect on speciation and extinction," Systematic Biology, vol. 56, no. 5, pp. 701-710, 2007.

[38] R. G. Fitzjohn, "Diversitree: comparative phylogenetic tests of diversification," R package version 0.9-3, 2012.

[39] R Development Core Team, "R: A language and environment for statistical computing," R Foundation for Statistical Computing, Vienna, Austria, 2008.

[40] Y. Yu, A. J. Harris, and X. J. He, "S-DIVA (Statistical DispersalVicariance Analysis): a tool for inferring biogeographic histories," Molecular Phylogenetics and Evolution, vol. 56, no. 2, pp. 848-850, 2010.

[41] F. Ronquist, "Dispersal-vicariance analysis: a new approach to the quantification of historical biogeography," Systematic Biology, vol. 46, no. 1, pp. 195-203, 1997.

[42] F. Ronquist, "Bayesian inference of character evolution," Trends in Ecology and Evolution, vol. 19, no. 9, pp. 475-481, 2004.

[43] R. H. Ree and S. A. Smith, "Maximum likelihood inference of geographic range evolution by dispersal, local extinction, and cladogenesis," Systematic Biology, vol. 57, no. 1, pp. 4-14, 2008.

[44] P. M. Beardsley, A. Yen, and R. G. Olmstead, "AFLP phylogeny of Mimulus section Erythranthe and the evolution of hummingbird pollination," Evolution, vol. 57, no. 6, pp. 1397-1410, 2003.

[45] R. Bleiweiss, “Origin of hummingbird faunas," Biological Journal of the Linnean Society, vol. 65, no. 1, pp. 77-97, 1998.

[46] S. D. Schoville, G. K. Roderick, and D. H. Kavanaugh, “Testing the "Pleistocene species pump" in alpine habitats: lineage diversification of flightless ground beetles (Coleoptera: Carabidae: Nebria) in relation to altitudinal zonation," Biological Journal of the Linnean Society, vol. 107, pp. 95-111, 2012.

[47] R. E. Sedano and K. J. Burns, "Are the Northern Andes a species pump for Neotropical birds? Phylogenetics and biogeography of a clade of Neotropical tanagers (Aves: Thraupini)," Journal of Biogeography, vol. 37, no. 2, pp. 325-343, 2010.

[48] J. M. Biernaskie and E. Elle, "A theory for exaggerated secondary sexual traits in animal-pollinated plants," Evolutionary Ecology, vol. 21, no. 4, pp. 459-472, 2007.

[49] E. C. Engel and R. E. Irwin, "Linking pollinator visitation rate and pollen receipt," American Journal of Botany, vol. 90, no. 11, pp. 1612-1618, 2003.

[50] M. Bosch and N. M. Waser, "Effects of local density on pollination and reproduction in Delphinium nuttallianum and Aconitum columbianum (Ranunculaceae)," American Journal of Botany, vol. 86, no. 6, pp. 871-879, 1999.

[51] M. A. Rodríguez-Gironés and L. Santamaría, "Why are so many bird flowers red?” PLoS Biology, vol. 2, no. 10, article e350, 2004.

[52] R. K. Vickery, "Speciation in Mimulus, or, can a simple flower color mutant lead to species divergence?" Great Basin Naturalist, vol. 55, no. 2, pp. 177-180, 1995.

[53] S. Y. Strauss, R. E. Irwin, and V. M. Lambrix, "Optimal defence theory and flower petal colour predict variation in the secondary chemistry of wild radish," Journal of Ecology, vol. 92, no. 1, pp. 132-141, 2004.
[54] S. D. Smith, R. E. Miller, S. P. Otto, R. G. FitzJohn, and M. D. Rausher, "The effects of flower color transitions on diversification rates in morning glories (Ipomoea subg. Quamoclit, Convolvulaceae)," in Darwin's Heritage Today, M. Long, H. Gu, Z. Zhou, and editors, Eds., pp. 202-226, Higher Education Press, Beijing, China, 2010.

[55] S. D. Smith, "Using phylogenetics to detect pollinator-mediated floral evolution," New Phytologist, vol. 188, no. 2, pp. 354-363, 2010.

[56] D. L. Rabosky, "Ecological limits on clade diversification in higher taxa," American Naturalist, vol. 173, no. 5, pp. 662-674, 2009. 

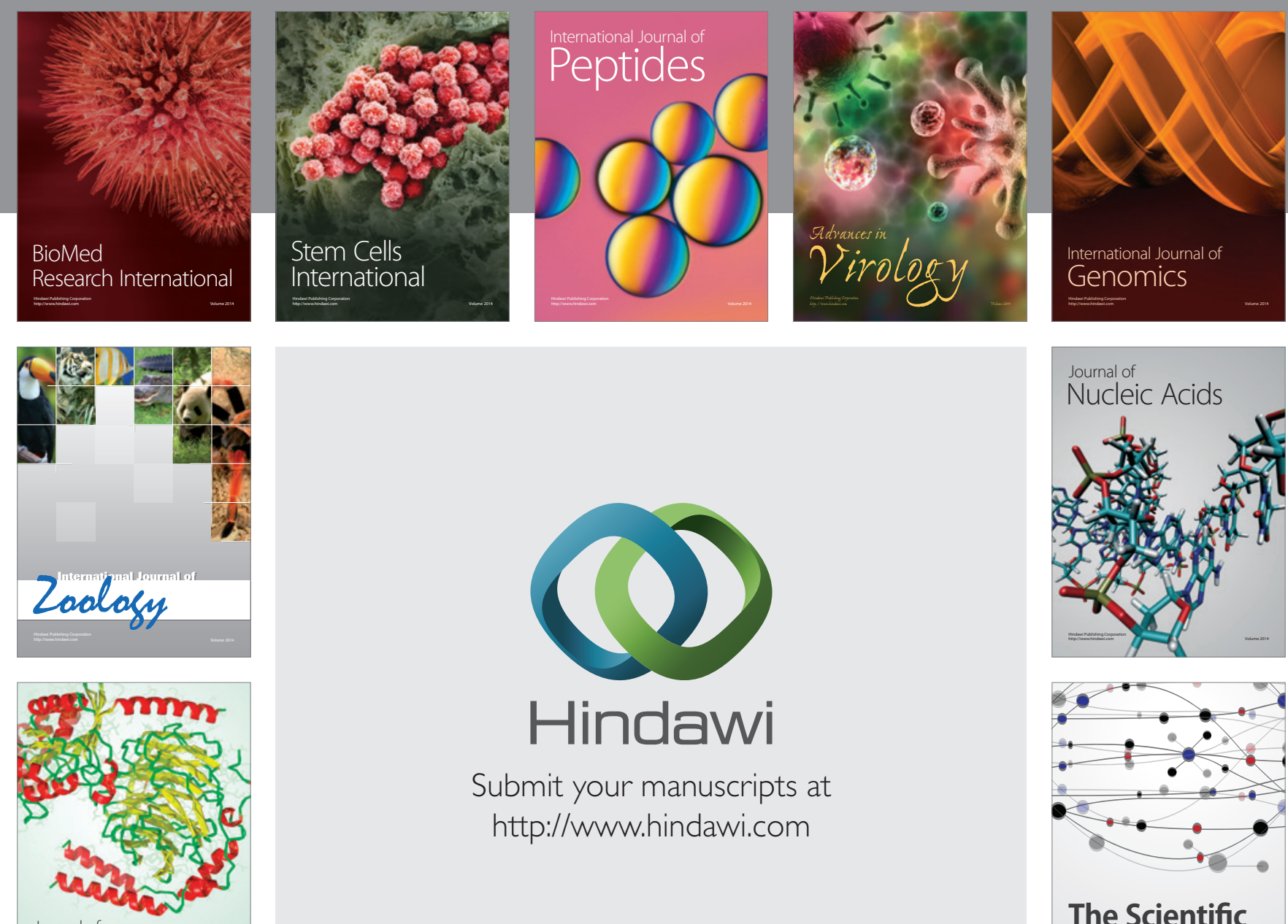

Submit your manuscripts at

http://www.hindawi.com

Journal of
Signal Transduction
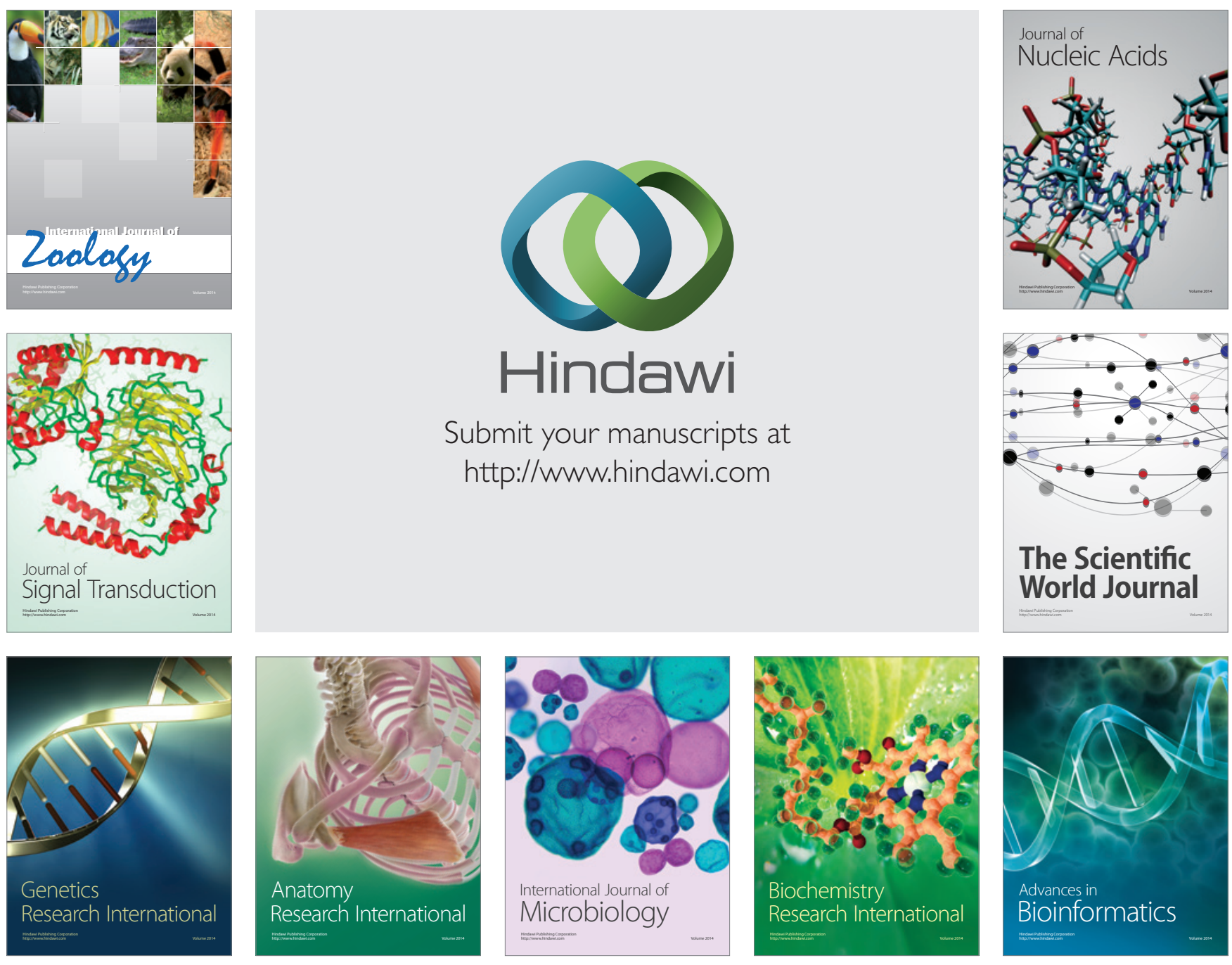

The Scientific World Journal
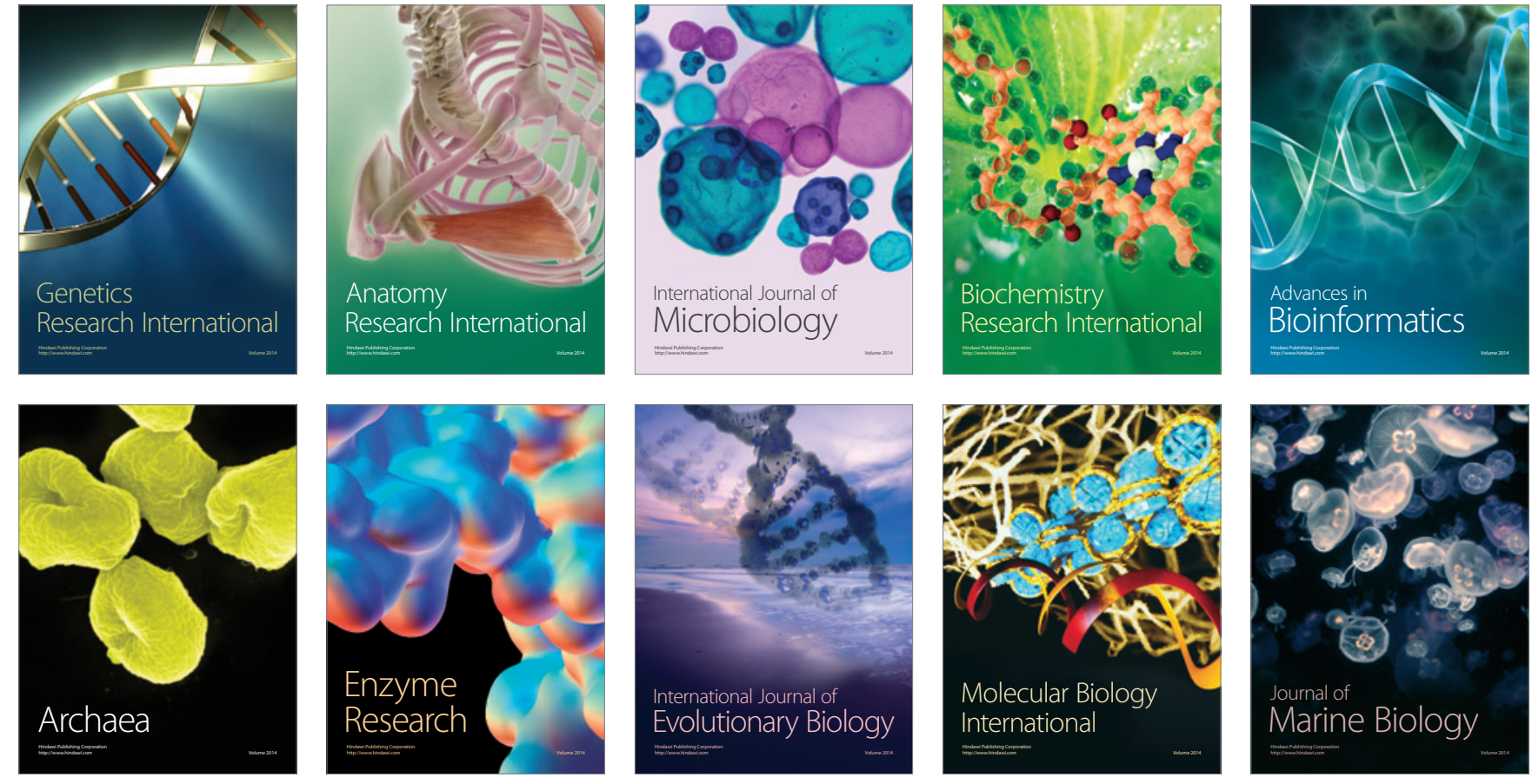